\title{
Functional Properties of Terry Towels
}

\author{
Krishna kumar $\mathrm{V}^{1 *}$ and Gokarneshan $\mathrm{N}^{2}$ \\ ${ }^{1}$ Principal, SMK Fomra Institute of technology, Chennai, India \\ ${ }^{2}$ Formerly Professor and Head, Department of Textile Technology, Park College of engineering and technology, Coimbatore, India
}

Submission: June 04, 2019; Published: July 10, 2019

*Corresponding author: Krishna kumar V, Principal, SMK Fomra Institute of technology, Chennai, India

\begin{abstract}
The article reviews the functional aspects of terry towels based on past research works. Different types of terry fabrics have been studied for effect of washing on some properties. Towels have been subjected to different washing cycles. After each cycle, the rate of water absorption, total amount of water absorbed, surface and compression characteristics have been assessed by gravimetric absorbency testing system, image analysis methods, and KES-FB 3 system respectively. Different theories and mechanisms of water absorption have been reviewed along with the key factors to improve the water absorption. Both dynamic and static water absorbency along with the initial time lag immerse are found to be the equally important attributes of the water absorbency performance of terry fabrics. The influence of some structural characteristics of terry fabrics on the rate of sorption have been studied.
\end{abstract}

Keywords: Terry fabric; Water absorption; Absorbency; Compressional characteristics; Serviceability; Dynamic sorption

\section{Introduction}

In the case of terry fabrics, a loop (pile) is formed by introduction of surplus yarn to impart specific function and different look. The wetting property of the fibers used is considered crucial in wet processing and functional performance. The surface of the fiber has to be wetted by liquid before being carried via pores between fibers through capillary action. The manner of flow of liquid through pores is determined by capillary force. The geometry of fiber assemblies, particularly, surface roughness and distribution of pore size [1]. The application of the terry fabric is determined by its end use. However, it does not give the data relating to the speed with which the terry fabric absorbs water or the manner in which water absorption changes with time. The rate of water absorption can be defined as the change in water absorption with time and is considered to be important. Also, the fabric surface is considered an important parameter affecting the absorption rate [2]. The static as well as dynamic absorption of water are collectively termed as 'absorbency'. The ability of the fabric to retain water relates to static absorbency and the rate at which the fabric absorbs water relates to the dynamic water absorbency. The research related to water absorbency of terry fabric got initiated with the conceptual development of absorbency, the theory of absorption, and appropriate absorption technique [3-7]. Initial work has been focused on absorbency performance of terry fabric after required chemical treatment and home laundering [8].

Subsequently research has been conducted to investigate the influence of various yarns on water absorbency properties along with the study of most appropriate test technique [9-11]. Through the use of surface tension, capillary theory, wicking, wetting, pore size and its distribution detailed investigations have been conducted [12-20].

\section{Design for Enhanced Serviceability}

The price and market for any product is mainly determined by its shelf life. When a fabric loses its aesthetic appearance, the customer considers it to be of no use. Ordinarily fabrics lose their appearance before getting worn out. Many scientific workers have studied the effect of different fabric softeners on water absorbency of terry fabric $[21,22]$. There is an increase of above $10 \%$ in the average water sorption following washing $[23,24]$. When the grey terry fabric is washed with washed with detergent and softened, there is increase in static water absorption to about 2.2 times [25]. The capability of water retention is enhanced by washing [26]. The present age requires properties like appearance, compression, texture, friction and so on, besides absorbency. The capacity of water retention and absorbance is influenced by repeated washes. Other characteristics of the terry fabric like compression, texture, friction, appearance and so on are influenced by home laundering. This aspect of home laundering and the properties have attracted attention during the recent times. Thus, attempt has been made to investigate the effect of home laundering on all the properties of terry fabric in a manner that the textile producer can understand the critical structural and material parameters that can be altered to improve their function. The effect of number of washing on 


\section{Current Trends in Fashion Technology \& Textile Engineering}

the water absorption rate of terry fabric has been found to be insignificant, since it has been seen that there is a marginal increase in water absorption rate up to 4 washes followed by gradual reduction as the number of washes increases. As the washes increase, the total amount of water absorbed increases. However, there is decrease in the total amount of water absorbed accompanied by reduction in absorption over 8 washes [27].

Increase of loop density on fabric surface can enable the fabric to endure more number of washes, without degradation in its properties. The loop length needs to be kept to maximum extent for achieving good after wash performance. For the loop lengths considered, the test results reveal that the fabric with $15 \mathrm{~mm}$ loop length exhibits better wash performance in comparison with that having loop length of 13 and $18 \mathrm{~mm}$ respectively.

\section{Performance}

Investigations have been made on static and dynamic water absorptions with regard to fabric construction and yarn properties. Over the past two decades, there have been remarkable advances focused on increasing the absorbency of terry fabrics [28-38]. In order to increase the absorbency of terry fabric, various types of yarns have been used as pile yarns. These include zero twist yarn, low twist yarn, wrap yarn and so on. But attempts have been taken to evolve a technique of enhancing the terry fabric absorbency. Present work has been focused on loop geometry and its effect on water absorbency [39]. There is considerable difference between wetting and wicking. Wetting is entirely based on characteristics of fiber surface and wetting liquid whereas wicking is based on the fiber arrangement and yarn into the fabric. The wetting characteristics of fibers strongly affect the wet processing and functional aspects of fibers. The surface of the fiber must be wetted by liquid prior being carried through the inter fiber pores by capillary action/force. The absorbency characteristic of fiber assemblies decides the geometry of fiber assemblies, more specifically roughness and pore size distribution. The static absorption is important in the determination of the terry fabric for different end uses. However, it does not provide any regarding the speed with which water is absorbed by, or way water absorption changes with time. It is termed as dynamic water absorption or rate of water absorption and is practically considered critical.

Hence the terry fabrics should be assessed about static and dynamic absorption. The maximum performance in absorbency is attained by means of pore size control and its distribution. Study has been carried out with objective of drawing conclusion relating to research work on enhancement of absorbency of terry towels and support the result by means of observation of the cross section of terry towels. Terry fabrics are produced with the objective of achieving high water absorbency. This is attained through longer, finer, and hydrophilic fiber for making soft, bulky, low twisted fine ring spun pile yarn, which in turn enables manufacturing terry fabric with high loop density, optimum loop length, high thread density, and loop shape factor. Post treatments like washing, tumbling, macerating, and hydrophilic softeners have been applied on terry fabrics to achieve improved water absorbency [40]. The loop shape factor is the important factor contributing to higher water absorbency based on recent research finding. The loop shape factor is affected by water absorbency performance of terry fabric. It is further influenced by loop shape factor which in turn is influenced by fiber and yarn characteristics, fabric constructional parameters, and wet processing treatments.

\section{Dynamic Sorption}

High water sorption is the major property of terry towels of interest to consumers. Terry fabrics outscore other fabrics regarding their sorption capacity because of the pile layer that forms greater sorption surface [41-43]. By means of suitable yarn and fabric structure it is possible to enhance the sorption surface. The porous spaces in the structure of the fabric and spaces between fibers in the yarn give determine the sorption capacity of a fabric. An appropriate loop height in combination with a high loop capacity determines the touch and the sorption capacity of the towels. Owing to its special properties like high absorbency, hypoallergenic properties, etc., cotton is generally used in production of terry fabrics. Other fibers like linen, regenerated cellulose (bamboo, modal, Lyocell and other fibers have been used during recent times [44]. Blends of cotton have been used with PVA fibers which are chemically soluble and have proved to be an innovative approach in production of terry fabrics. The PVA fibers dissolve during the finishing process. The towels that have been finished have greater volume and very soft in feel [45]. The water sorption of textile structures can be considered and assessed relating to some aspects including wetting ability, capillary wicking, sorption capacity, moisture and thermal comfort, etc. There are several studies relating to these aspects and the method adopted and properties become different based on the objective of the researchers [46-50].

Properties such as enhanced rate of sorption and ability to quickly absorb, retain and transfer liquid water from various surfaces like human skin, dishes, and furniture are the critical factors to be considered in terry fabrics. These are crucial to satisfy the needs in their area of application and comfort. It is possible to determine the wicking properties by means of the capillary activity. Various techniques of measurement of capillary ability are available. Based on a Bulgarian State Standard the test samples are vertically aligned strips, whose bottom ends are immersed in water solution containing potassium dichromate. The raised water is noted. The test sample must be placed horizontally to avoid the gravity force created by the water column and the ends must get immersed in water. The technique permits the measurement of the water sorption. Both these techniques determine the distance wetted. The second one has greater accuracy and yields greater information relating to the sorption process. It is possible to gravimetrically measure the wettability. The test material is placed horizontally by virtue of its contact with water surface absorbs water. The weight of the absorbed water over time is recorded. There is a new technique to measure the rate of sorption and the wetted area by means of resistance 
sensors [51,52]. The upper surface of the test specimen is wetted by the moisture management tester and the water transfer determined. The properties determined enable the prediction of the moisture comfort of the terry fabric.

A more accurate technique has been offered which directly binds the water absorption and transfer with the warm-cool feeling of products [53]. The thermal absorptivity parameter has been introduced. Less heat exchange and enhanced feel imply a lower coefficient. Study has been conducted with the aim of knowing the influence of critical structural properties of terry fabrics on the sorption ability and the rate of sorption. These are as follows

a) Manufacture of terry fabrics through alteration of the weft density and the pile height.

b) Evolving an experimental norm for dynamic measurement of water sorption.

c) Measurement of the water quantities, that is absorbed by the fabric with time duration and

d) Sorption rate calculation.

The findings have been as follows

a) Greater density of weft results in higher water mass absorbed by the terry fabrics as it enhances the amount of fibrous substance.

b) Alteration of the density of weft from 160 - 200 threads / $\mathrm{dm}$ on the water mass absorbed in 5 minutes increases almost twofold in warp and almost six-fold in weft direction respectively.

c) The alteration in weft density changes the gradient of sorption rate during various time intervals. The sorption rate decreases abruptly with time at lower densities, whereas there is a more gradual reduction at the high density.

\section{Conclusion}

Cotton terry fabrics have been produced with various construction have been produced and the influence of washing treatment on water absorbency, surface and compression characteristics have been investigated. Terry fabrics with identical yarn and fabric parameters have been washed as per industrial norms, in order to establish the optimum loop length and loop density at which they can withstand maximum number of washing cycles without affecting water absorbency, surface and compression characteristics. In order to enhance the durability of terry fabric, fabrics with various loop length and loop density have been investigated for optimization of these two critical factors. Such investigation would certainly enable enhancing the durability of terry fabric, developing high quality towel fabric by providing information on absorbency, surface and compression characteristics of fabric before and after washing along with the values of loop length and loop density. A critical analysis of all the information relating to the evolved theories and mechanisms of water absorption in terry fabric enables to understand and choose the most realistic theory and mechanism of water absorption of terry fabric which will be helpful in designing the most absorbent terry fabric. High loop shape factor is the key to improve the absorbency behavior of the terry fabric. In order to support the concluding theory, mechanism and results, cross section images of different terry fabrics have been studied. The effect of certain structural properties of terry fabrics on the rate of sorption has been studied.

\section{References}

1. Buras EM, Goldthwait CF, Kramer RM (1950) Measurement and Theory of Absorbency of Cotton Fabrics. Textile research Journal 20(4): 239-248.

2. Murphy BG, Macromac AR (1958) The Absorbency of Terry Towels: Part I: Effect of Home Laundering. Textile research journal 28(4): 337342.

3. Stevenson L, Lindsay (1926) M Journal of home economics 18: 193.

4. Larose P (1942) American dyestuff reporter 31: 105.

5. Holland VB (1943) Textile Rec 38: 61.

6. Jackson EC, Roper ER (1949) American dyestuff reporter 38: 397.

7. Buras EM, Goldthwait CF, Kraemer RM (1950) Textile research journal 20: 239.

8. Aycock B (1972) Textile chemistry and color. 4: 16.

9. Lord PR, Mohamed MH, Ajgaonkar DB (1974) The Performance of Open-End, Twistless, and Ring Yarns in Weft Knitted Fabrics. Textile research journal 44(6): 516.

10. Cary RT, Sproles G (1979) Textile research journal 49: 691.

11. Swani NM, Hari PK, Anandjiwala R (1984) Performance Properties of Terry Towels Made from Open-end and Ring-Spun Yarns. Indian journal of Textile research 9: 90-94.

12. Akira S, Kumiko A, Naomi M (1190) Journal of Japan research association textile end uses 31: 48.

13. Bozgeyik K (1991) A quantitative investigation about towels, MSc Dissertation, Institute of Natural and applied science. Izmir.

14. Hseish YL, Yu B (1992) Textile research journal 62: 677.

15. Hseish YL (1995) Liquid Transport in Fabric Structures. Textile research journal 65: 299-307.

16. Kissa E (1996) Wetting and Wicking. Textile research journal 66(10): 660-668.

17. Jacques A, Schramm CJ (1997) in Liquid detergents. In: Lai KY (Eds.), pp. 133.

18. Nostadt K, Zyschka RU (1997) Colourage. 44: 53.

19. Crow RM (1998) Textile Research Journal 68: 280.

20. Kadolph SJ (1998) Quality assurance for textiles and apparel. Iowa State University, New York, USA, pp. 128.

21. Hseih YL, Thompson J, Miller A (1996) Water Wetting and Retention of Cotton Assemblies as Affected by Alkaline and Bleaching Treatments. Textile Research Journal 66(7): 456-464.

22. Meeran PVD, Cocquyt J, Flores S, Demeyere H, Declercq M (2002) Water Wetting and Retention of Cotton Assemblies as Affected by Alkaline and Bleaching Treatments. Textile research journal 72(5): 423-428. 


\section{Current Trends in Fashion Technology \& Textile Engineering}

23. Izabela FW, Marek S (2004) Fibres and textiles in eastern Europe. 12 40.

24. Militiky J, Bajzik V (1997) International journal of clothing science and technology 9: 193.

25. Petrulyte S, Baltakyte R (2009) Fibres and Textiles in eastern Europe. 17(3): 60-65.

26. Petrulyte S, Naslineine J (2010) Fibres and Textiles in eastern Europe. 18: 93.

27. Singh JP, Behera BK (2018) Static Water Absorption in Fabrics of Different Pile Height. Indian journal of fibre and textile research 43: 415420.

28. Yamamoto T, Miyazaki K, Ishizawa H, Matsumoto Y (2005) Journal of textile machinery society Japan. 58: s147.

29. Karahan M, Eren R (2006) Experimental Investigation of the Effect of Fabric Parameters on Static Water Absorption in Terry Fabrics. Fibres and Textiles in eastern Europe 14(2): 59-63.

30. Nyoni AB, Brook D (2006) Journal of textile institute. 97(2): 119-128.

31. Karahan M (2007) Fibres and Textiles in eastern Europe. 15: 74

32. Petrulyte S, Baltakyte R (2008) Analysis of Dynamic Water Absorption Phenomenon in Pile Fabrics. Tekstil: Journal of Textile \& Clothing Technology 57(5): 211-217.

33. Petrulyte S, Baltakyte R (2009) Liquid Sorption and Transport in Woven Structures. Fibres and Textiles in eastern Europe 17(2): 39-45.

34. Petrulyte S, Baltakyte R (2009) Static Water Absorption in Fabrics of Different Pile Height. Fibres and Textiles in eastern Europe 17(3): 6065.

35. Petrulyte S, Naslineine J (2010) Fibres and Textiles in eastern Europe 18: 93.

36. Behera BK, Singh JP (2004) Research journal of textile and apparel 18: 113.

37. Sekerden FW (2012) Fibres Science 44: 189.

38. Singh JP (2014) Indian institute of technology, Delhi, India.

39. Singh JP, Behera BK (2012) Proceedings, $19^{\text {th }}$ Strutex (Technical university of Liberec, Czech Republic, Europe, p. 59.
40. Singh JP, Behera BK (2015) Performance of terry towel. Indian journal of fibre and textile research 40:112-121.

41. Karahan M (2007) Experimental investigation of the effect of fabric construction on dynamic water absorption in terry fabrics. Fibres \& Textiles in Eastern Europe 15(3): 74-80.

42. Karahan M, Eren R, Alpay HR (2005) An investigation into the parameters of terry fabrics regarding the production. Fibres \& Textiles in Eastern Europe 13(2): 21-25.

43. Sharma UC, Madhusoothanan M (2010) Terry towel: some developments for quality improvement.

44. Yilmaz ND, Powel NB (2005) The technology of terry towel production Journal of Textile and Apparel, Technology and Management. 4(4): $1-46$.

45. Frontezak-Wasiak I, Snycerski M (2004) Use properties of terry woven fabrics. Fibres \& Textiles in Eastern Europe 12(1): 40-44.

46. Petrulyte $S$, Baltakyte R (2008) Investigation into the wetting phenom enon of terry fabrics. Fibres \& Textiles in Eastern Europe 16(4): 62-66.

47. Petrulyte S, Baltakyte R (2009) Liquid sorption and transport in woven structures. Fibres \& Textiles in Eastern Europe 17(2): 39-45.

48. Petrulyte S, Baltakyte R (2009) Static water absorption in fabrics of different pile height. Fibres \& Textiles in Eastern Europe 17(3): 60-65.

49. Petrulyte S, Nasleniene J (2010) Investigation of the liquid retention capacity of terry fabrics. Fibres \& Textiles in Eastern Europe 18(5): 9397.

50. ASTM D4772-09 (2009) Standard Test Method for Surface Water Absorption of Terry Fabrics (Water Flow)

51. Hu J, Li Y, Yeung K, Wong A, Xu W (2005) Moisture management tester: a method to characterize fabric liquid moisture management properties. Textile Research Journal 75(1): 57-62.

52. Hes L (1999) Optimization of shirt fabrics composition from the point of view of their appearance and thermal comfort. International Journal of Clothing Science \& Technology 11(2): 105-119.

53. Diana Stoyanova Germanova- Krasteva Galya Dimitrova Kandzhikova Atanas Grigorov Bochev (2013) Influence of terry fabrics structure on dynamic sorption. International Journal of Clothing Science and Technology 25(4): 243-256

\section{Your next submission with Juniper Publishers} will reach you the below assets

- Quality Editorial service

- Swift Peer Review

- Reprints availability

- E-prints Service

- Manuscript Podcast for convenient understanding

- Global attainment for your research

- Manuscript accessibility in different formats

( Pdf, E-pub, Full Text, Audio)

- Unceasing customer service

Track the below URL for one-step submission https://juniperpublishers.com/online-submission.php 